\title{
Stochastic Nature of Salt Mass Transport in Porous Media Under Unstable Conditions
}

\section{Kamal Mamoua*, Ashok Pandit and Howell Heck}

Department of Civil Engineering, Florida Institute of Technology, Melbourne, FL 32901, USA

\begin{abstract}
The two main transport mechanisms that occur simultaneously under unstable flow conditions are transport of saltwater from an overlying salt source to the porous media, and transport of salt through the porous media These mechanisms were simultaneously studied through two fixed mass experiments conducted over 15 days. The transport through the porous media was also studied via three continuous injection experiments lasting between 5 to 29 days. There was no hydraulic gradient across the porous media in any of the experiments. Experiments were conducted in a $1 \mathrm{~cm}$ thick plexiglass rectangular sand column $(1.70 \mathrm{~m} \times 0.61 \mathrm{~m} \times 0.61 \mathrm{~m})$. The saline source concentration was $36 \mathrm{~g} / \mathrm{l}$, and the source heights were $4.5 \mathrm{~cm}$. The sand porosity and hydraulic conductivity were $32 \%$ and $9.0 \mathrm{~m} / \mathrm{d}$, respectively. The rate of mass transport from the source to the porous media was observed by measuring the salt concentration within the source, while the salt transport through the porous media was documented by measuring breakthrough curves at five locations within the sand column. Fixed mass experiment results, using mass analysis, showed that the salt transport from the source to the porous media was deterministic since both experiments produced identical rates of mass transport from the source to the porous media, the salt transport through the porous media was stochastic since the observed breakthrough curves at the five locations were considerably different. The breakthrough curves measured in three identical continuous injection experiments were also very different supporting the results of the fixed mass experiments. The implications of these findings are that, under unstable conditions, one can predict the salt mass that would enter from a salt source into the underlying porous media with certainty, one cannot predict the rate or pattern of salt transport through the porous media itself.
\end{abstract}

Keywords: Physical model; Salt transport; Porous media; Breakthrough curves; Stochastic; Fingering; Free convection

\section{Introduction}

\section{Forced, free and mixed convective flow}

There are many real-world situations where a mass of relatively heavier fluid overlies a porous media containing a lighter fluid. For example, this is fairly common at landfills and waste dump sites [1-3], saline disposal basins [4], seawater inundation along coastal aquifers [5], and in estuaries [6-11]. Typically, when saltwater and freshwater are in contact with each other, the groundwater flow is due to natural hydraulic gradients, and the movement of the fluid is termed "forced" convection. Under forced convective conditions, in the absence of any ambient groundwater velocity, the flux of salt can be regarded as the sum of molecular diffusion and mechanical dispersion [12]. However, when a heavier fluid such as saltwater overlies relatively fresher, and lighter groundwater, the heavier fluid may establish additional hydraulic gradients, which lead to "convective" dispersion; a term used by Bachmat et al. [12]. Subsequently, the term "free" convection has also been used instead of convective dispersion [13]. When both forced convection and free convection operate together in a groundwater system, the resulting flow is termed mixed convective flow [13]. It has been noted by Wooding [14] and others that the presence of a heavier fluid on top of a lighter fluid is potentially unstable, but does not always result in free convective transport.

\section{Past experimental and numerical studies}

There are two main transport mechanisms that occur under unstable flow conditions a) the transport of saltwater from the overlying salt source, which is termed as "Source" from here on, to the underlying porous media, and b) the transport of the saltwater through the porous media. These transport processes have been investigated by several researchers via laboratory and/or numerical experiments e.g., [12,14-
23]. In many of these physical model studies, heavier fluids, containing salt, were placed on top of a column or tank filled with saturated porous media containing freshwater. Some of these experiments were continuous injection experiments in which the salt concentration of the heavier fluids was kept constant $[7,16,17,23]$, while others were fixed mass experiments in which the overlying, heavier fluid has a fixed mass of solute which was transported into the porous media over time $[12,14,18,20]$.

Some of the key findings regarding the transport of salt through the porous media are: 1) under free convection conditions, saltwater moves through the porous media in the form of lobe shaped fingers, and convective dispersion, as opposed to molecular and mechanical dispersion, is the key transport mechanism $[12,15,20], 2)$ the number and configuration of these fingers were not reproducible in practical experiments [12,15], 3) fingering causes rapid and erratic redistribution of solutes [15], and the salt travels faster and farther when fingers are formed as opposed to when the transport is due to mechanical dispersion $[15,17], 4)$ salt plumes move faster and farther with increasing source concentrations $[4,15], 5)$ fingers tend to coalesce as they move greater distances $[14,16,17]$, and 6) not only does the salt move faster and farther once it enters the porous media, the total mass of the salt transported

*Corresponding author: Kamal Mamoua, Department of Civil Engineering, Florida Institute of Technology, Melbourne, FL 32901, USA, Tel: +132144229; E-mail: kmamoua2012@my.fit.edu

Received June 23, 2017; Accepted June 28, 2017; Published July 04, 2017

Citation: Mamoua K, Pandit A, Heck H (2017) Stochastic Nature of Salt Mass Transport in Porous Media Under Unstable Conditions. Hydrol Current Res 8: 278. doi: $10.4172 / 2157-7587.1000278$

Copyright: $\odot 2017$ Mamoua K, et al. This is an open-access article distributed under the terms of the Creative Commons Attribution License, which permits unrestricted use, distribution, and reproduction in any medium, provided the original author and source are credited. 
during free convection is typically far greater than transported by diffusion [23]. Fingering was observed in most of these experiments either visually through photographs $[12,14,15,17,18]$, or by some sort of digital processing [20,22]. Mulqueen et al. [24] stated that the nonlinear dynamics of the unstable system made it impossible to predict where a finger would grow or how it might develop. This phenomenon was also observed by Schincariol et al. [15] who photographed plume movement under unstable conditions with a continuous $\mathrm{NaCl}$ source and noted that position of the instabilities was not the same when an experiment with a source concentration of $2000 \mathrm{mg} / \mathrm{l}$ was repeated.

The observations by Mulqueen et al. [24] and Schincariol et al. [15] indicate that when the salt transport through the porous media is due to free convection, it should be expected that when experiments are repeated, the pattern of salt transport through the porous media would be vastly different since even minor differences in the packing of the porous media can create vastly different fingering patterns leading to completely different patterns of transport. In other words, if two experiments are conducted with exactly identical conditions in terms of the type of mass source, and porous media characteristics such as hydraulic conductivity, porosity etc., the transport through the porous media may be different indicating that the salt transport through the porous media is stochastic in nature and cannot be predicted.

To our knowledge, in none of the above-mentioned experiments, except for one study [18], were experiments duplicated to quantitatively assess if the salt transport through the porous media was, or was not, stochastic in nature. In other words, no attempt has been made to repeat an experiment to determine if the mass transport is similar or different as in the previous experiment. Wood et al. [18] did repeat a fixed mass experiment on a $15-\mathrm{cm}$ diameter cylindrical column with a length of $0.9 \mathrm{~m}$, using Calcium Chloride as the source fluid, and determined the breakthrough curves at the outlet of the column in response to the initial concentration in the source fluid which was Calcium Chloride. Wood et al. [18] found that the breakthrough curves from the two experiments were quite similar. However, their experiments did not determine the salt transport inside the column but rather at the outlet of the column. It is likely, that the salt coalesced as it travelled through the column, and the result of the coalescing process may have yielded similar breakthrough curves for both experiments at the column outlet, even though the salt transport within the column may have been vastly different. Furthermore, the experimental system of Wood et al. [18] was a mixed convective system as they applied a hydraulic gradient across the porous medium. It is possible that the presence of the hydraulic gradient may have significantly affected the transport mechanism through the porous media resulting in similar breakthrough curves for both experiments. The present study extends the work of Wood et al. [18] by measuring and comparing the breakthrough curves at multiple ports (five) within the column, instead of just at the outlet, for both fixed and continuous injection experiments. Moreover, no hydraulic gradient was applied in the experiments conducted in this study, so this study is the first one that examines the nature of salt transport within the porous media under strictly free convective flow.

\section{Objectives}

The main objective of this paper was to conduct duplicate fixed mass and continuous injection experiments to determine if the salt transport through the porous media is stochastic or deterministic under free convection.

\section{Methods}

\section{Description of the physical model}

Experiments were conducted in a $1-\mathrm{cm}$ thick plexiglass column which has a height of $1.83 \mathrm{~m}$ and a base of $0.61 \mathrm{~m}$ by $0.61 \mathrm{~m}$ as shown in Figure 1. The column is supported by a metal stand and consists of a source area at the top where the saline solutions were placed, and a drain valve at the bottom. For convenience, the saline solutions placed at the top of the column will be referred to as source solutions in this paper while the column containing the porous media will be referred to as the sand column. The height of the source solutions can be varied to a maximum height of $13 \mathrm{~cm}$ using an adjustable overflow pipe. The column has of five sampling ports, $P_{1}$ to $P_{5}$, located at fairly uniform distances below the source as shown in Figure 1. All ports are connected to a sampling probe that can traverse a distance of $30 \mathrm{~cm}$, i.e., to the center of the column.

The sand used in this study was 40F from Standard Sand and Silica Company, with an effective size $\left(\mathrm{d}_{10}\right)$ of $0.17 \mathrm{~mm}$, and a uniformity coefficient of 1.8. The sand porosity was obtained by filling a known volume of sand in a graduated cylinder and adding water to the sand in increments until the sand column was fully saturated. The porosity was calculated as the ratio of the volume of water added to the sand volume. The experiment was repeated 5 times and the estimated porosity values ranged from $31.7 \%$ to $32.2 \%$ with an average porosity of approximately $32 \%$ with a standard deviation of 0.21 . The hydraulic conductivity of the sand was determined by conducting constant head tests in the previously described sand column. The experiment was repeated five times and the range of hydraulic conductivity values measured were from $8.6 \mathrm{~m} / \mathrm{d}$ to $9.2 \mathrm{~m} / \mathrm{d}$ with an average of $9.0 \mathrm{~m} / \mathrm{d}$ and a standard deviation of 0.20 .

\section{Experimental Procedure and Description of Experiments}

Sand was placed inside the sand column in three steps. First, sand was filled up to a depth of $1.70 \mathrm{~m}$ in increments of $25 \mathrm{~cm}$. Each increment was fully saturated with water before adding the next increment of sand. Saturation was assured by allowing water to stand on top of the sand for a period of one day and observing the water level. The sand was considered saturated if the water level did not drop. This procedure was repeated after adding every $25 \mathrm{~cm}$ of sand increment and the entire process took approximately one week. Second, water was passed through the sand column until the inflow was equal to outflow. Water was allowed to flush through the sand column for a period of six hours after inflow became equal to outflow to ensure that there were no structural changes in the sand column as a result of the fluid passing through the porous medium, and to remove any entrapped air bubbles. Third, the drainage valve was closed, and the source area was filled with fresh water to the desired level. The water was allowed to sit in the sand column for a period of one week to ensure that the water loss was only due to evaporation and that the sand column was fully saturated and devoid of any air pockets. The source area was covered by a thin plastic sheet to minimize evaporation losses and no evaporation.

\section{Porous media properties}

Losses were observed over the entire duration of the experiments. Salinity and temperature measurements were taken using a YSI salinity meter which measured conductivity and converted it into salinity. The fixed mass experiments were started by adding the saline water solution (Sodium Chloride) to the source area to the desired depth and this procedure took less than one minute. The Continuous Injection Experiments were started by adding saline water at a concentration of 
$36 \mathrm{~g} / \mathrm{l}$ into the source area from a storage tank to a depth of $4.5 \mathrm{~cm}$; this procedure took less than one minute. The salinity concentration in the source area was maintained by continuously adding saline water to the source area by a variable-speed Peristatic Minipump. It should be noted that the freshwater salinity in the porous media was $0.3 \mathrm{~g} / \mathrm{l}$.

Salinity and temperature measurements at each port were taken by extracting samples from the port locations using the needles attached to each port. Sample sizes were $35 \mathrm{ml}$. Extracted samples were injected back at the port location after taking salinity and temperature measurements which took less than a minute. Source salinity measurements were taken by inserting the salinity meter into the source and no samples had to be extracted. The sampling schedule for both the fixed mass and continuous injection experiments is shown in Table 1. Salinity measurements at the ports for both experiments 1 and 2 were taken every six hours for the first two days, every 12 hours from the $2^{\text {nd }}$ day to the $10^{\text {th }}$ day, and every 24 hours after that. Salinity samples at the source were taken after $1,5,15,20,30,45,60$ minutes, and then at 2,4 , $6,12,18,24$ hours. After 24 hours, salinity was measured at intervals of 6 hours on the second day, and at intervals of 12 hours from the $2^{\text {nd }}$ day to the $10^{\text {th }}$ day, and every 24 hours for the rest as shown in the Table 1.

One fixed mass and one continuous injection experiment, having durations $\left(t_{d}\right)$ between 15 to 29 days, were conducted with the source height, $\mathrm{h}_{0}$, of $4.5 \mathrm{~cm}$, an initial source concentration, $\mathrm{C}_{\mathrm{s} 0}$, of $36 \mathrm{~g} / \mathrm{l}$, as shown in Table 2. Experiment 1 was a fixed mass experiment and was repeated once, and the two experiments are termed Experiments 1a and $1 \mathrm{~b}$ in Table 2, while Experiment 2, a continuous injection experiment, was repeated twice, and the three experiments are termed as Experiments 2a, 2b and 2c in Table 2. Experiment 1 was stopped after 15 days when it was observed that the daily mass exiting from the source into the porous media was less than $0.3 \%$. Experiments $2 \mathrm{a}$ and $2 \mathrm{~b}$ were terminated after 28 and 29 days because there was negligible change in the salinity at each of the five ports and a quasi-steady-state had been reached. Experiment $2 \mathrm{c}$ was conducted to ensure that the breakthrough curves were oscillating and unpredictable in the beginning, hence it was stopped after five days.

\section{Analyses and Results}

\section{Comparison of breakthrough curves and mass analysis for Experiment 1}

The five breakthrough curves measured at each port for Experiments

\begin{tabular}{|c|c|c|}
\hline Duration (day) & At Ports & At Source \\
\hline $0-0.25$ & Every $6 \mathrm{~h}$ & $1,5,15,30,60,120,240$ and 360 \\
\hline $0.25-2$ & Every $6 \mathrm{~h}$ & every $6.0 \mathrm{~h}$ \\
\hline $2-10$ & Every $12 \mathrm{~h}$ & every $12 \mathrm{~h}$ \\
\hline $10-$-End & Every $24 \mathrm{~h}$ & every $24 \mathrm{~h}$ \\
\hline
\end{tabular}

Table 1: Sampling Schedule at Source and Ports for Experiments 1 and 2.

\begin{tabular}{|c|c|c|c|c|}
\hline Experiment No & $\mathbf{h}_{\mathbf{o}} \mathbf{c m}$ & $\mathbf{C}_{\mathbf{s} \mathbf{0}} \mathbf{g} / \mathbf{l}$ & $\mathbf{t}_{\mathbf{d}}$ day & Source condition \\
\hline $1 \mathrm{a}$ & 4.5 & 36 & 15 & $\mathrm{~F}$ \\
\hline $1 \mathrm{~b}$ & 4.5 & 36 & 15 & $\mathrm{~F}$ \\
\hline $2 \mathrm{a}$ & 4.5 & 36 & 29 & $\mathrm{C}$ \\
\hline $2 \mathrm{~b}$ & 4.5 & 36 & 28 & $\mathrm{C}$ \\
\hline 2c & 4.5 & 36 & 5 & $\mathrm{C}$ \\
\hline
\end{tabular}

$h_{\mathrm{o}}=$ source depth; $\mathrm{C}_{\mathrm{so}_{0}}=$ initial source concentration; $\mathrm{t}_{\mathrm{d}}=$ duration of experiment; $\mathrm{F}=$ fixed source mass; $\mathrm{C}=$ continuous source mass

Table 2: Physical Lab Experiment Descriptions.
$1 \mathrm{a}$ and $1 \mathrm{~b}$ are shown in Figure $2 \mathrm{a}$ and $2 \mathrm{~b}$, respectively. The breakthrough curves measured at Ports 1 through 5 during Experiments $1 \mathrm{a}$ and $1 \mathrm{~b}$ are individually compared in Figures $3-7$, respectively. It should be noted that since the ports are located in the center of the column, these breakthrough curves reflect the salt transport through the center of the column. The breakthrough curve comparisons indicate that:

- The breakthrough curves for the two experiments are vastly different at Ports 1 to 4 (Figures 3-6) but become fairly similar at Port 5 (Figure 7). The similarity of the two breakthrough curves at Port 5 is comparable to the similarities that were also observed by Wood et al. [18] at their column outlet, since Port 5 is the lowest port and closest to the outlet of the column. These comparisons indicate that the salt distribution in the porous media can be vastly different both temporarily and spatially if the experiments are repeated, but may show similarities near the outlet of the column. The similarity in the breakthrough curves of Experiments 1a and 1b, at Port 5, could be due to the coalescing of the fingers that occurs as the salt moves downward in the column, resulting in the salt moving more as a "front", as in stable systems, instead of via fingers as observed in unstable systems.

- A comparison of the breakthrough curves for Ports 1 and 5 in both Experiment 1a (Figure 2a) and Experiment 1b (Figure $2 \mathrm{~b}$ ) indicates that the concentration at the lower port (Port 5) became higher than that of an upper port (Port 1) towards the end of the experiment. These phenomena indicate that the saline water in the source was "sinking" like a dense nonaqueous phase liquid (DNAPL), and collecting at the bottom of the column, which is very similar to the characteristics exhibited by a DNAPL as it moves down in the porous media. The difference between the DNAPL and the salt in this case is that while the DNAPL moves through the macro-pores in the porous media, the salt moves in the form of fingers.

- The higher concentrations in the lower ports is indicative that the main salt transport mechanism was not molecular diffusion, because in that case the salt concentration at the lower ports would always be smaller than those at the upper ports.

- Another key difference in the salt transport between Experiments $1 \mathrm{a}$ and $1 \mathrm{~b}$ can be demonstrated by the "arrival times" noted at each port as shown in Table 3. Arrival time at a port is defined as the time when the salt concentration at the port was first noticed to be greater than the salt concentration in the fresh water which was $0.3 \mathrm{~g} / \mathrm{l}$.

- A comparison of the arrival times for the Experiments 1a and $1 \mathrm{~b}$ indicates that they are vastly different; for example, the salt reached Port 4 after nine days and four days, respectively. Furthermore, the salt arrived at Port 5 earlier than Port 4 in Experiment 1a whereas that was not the case in Experiment $1 \mathrm{~b}$.

A mass analysis was also performed to examine the salt distribution within the porous media in Experiments $1 \mathrm{a}$ and $1 \mathrm{~b}$, and the results of the mass analysis are shown in Figure 8 . Figure 8 shows the initial

\begin{tabular}{|c|c|c|c|c|c|}
\hline $\begin{array}{c}\text { Experiment } \\
\text { No. }\end{array}$ & $\begin{array}{c}\text { Port 1 } \\
\text { Day (hr) }\end{array}$ & $\begin{array}{c}\text { Port 2 } \\
\text { Day (hr) }\end{array}$ & $\begin{array}{c}\text { Port 3 } \\
\text { Day (hr) }\end{array}$ & $\begin{array}{c}\text { Port 4 } \\
\text { Day (hr) }\end{array}$ & $\begin{array}{c}\text { Port 5 } \\
\text { Day (hr) }\end{array}$ \\
\hline 1a & $0.25(6)$ & $1.375(33)$ & $3.5(84)$ & $9(216)$ & $6(144)$ \\
\hline 1b & $0.25(6)$ & $1.0(24)$ & $2(48)$ & $4(96)$ & $5(120)$ \\
\hline \multicolumn{7}{|c}{ Table 3: Arrival time at each port for Experiments 1a and 1b. }
\end{tabular}



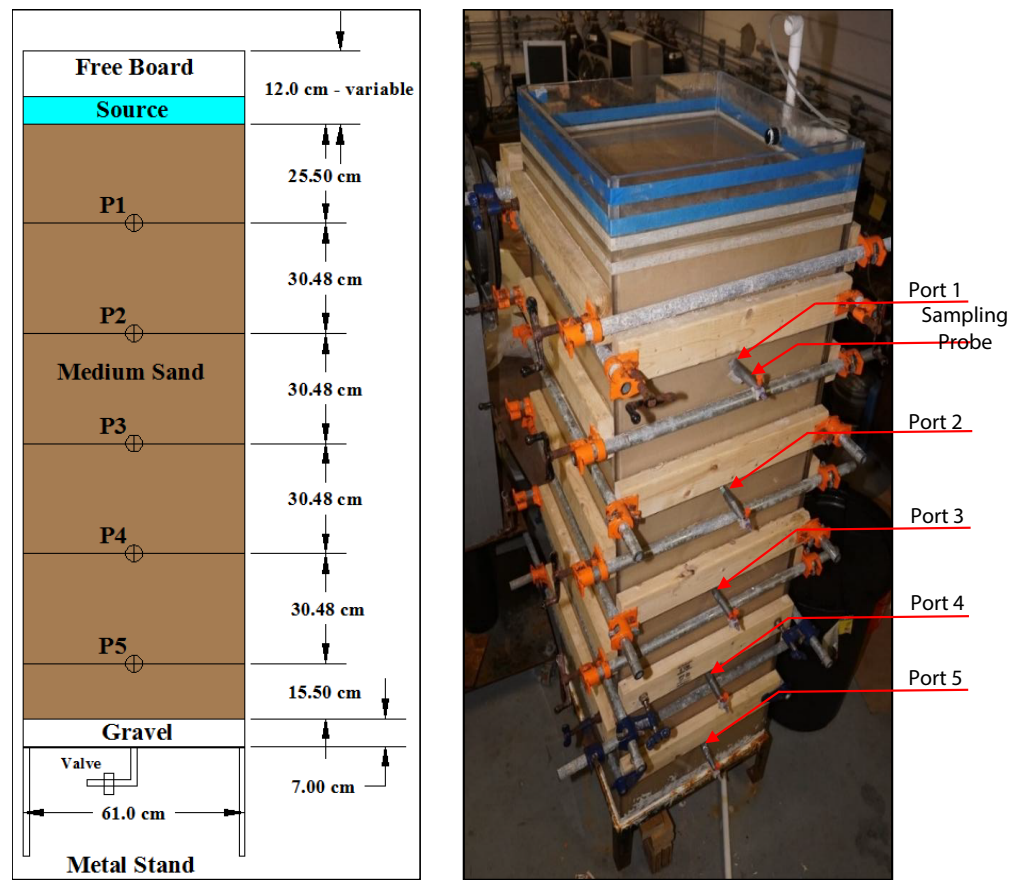

Figure 1: A schematic diagram and photograph of the physical model used for study.
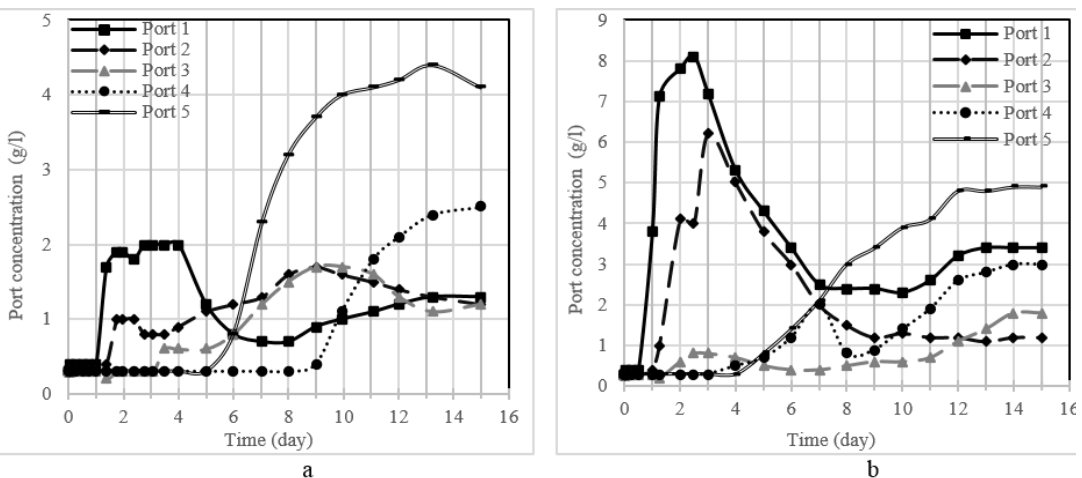

Figure 2: Measured breakthrough curves at five ports for a) Experiment 1a, b) Experiment $1 b$.

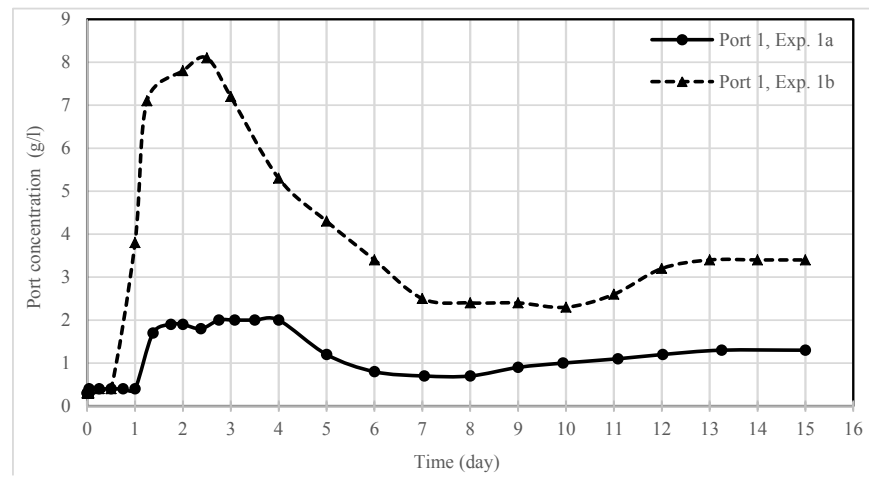

Figure 3: Comparison of breakthrough curves at Port 1 for Experiments 1a, and $1 \mathrm{~b}$.

( $\mathrm{t}=0$ days) mass distribution within the column and the source, and the gradual changes in the mass distribution after $1,5,10$ and 15 days. The mass values shown in these tables were determined by assigning a volume to each port. For example, the volume assigned to Port 1 extended from the source to halfway between Port 1 and 2. Similarly, the volume assigned to Port 2 extended from the halfway point of Ports 
1 and 2 to the halfway points of Ports 2 and 3. The volume assigned to Port 5 extended from the halfway point of Ports 4 and 5 to the bottom of the column. The mass attributed to each port was determined by multiplying the volume of water associated with each port by the salinity concentration measured at the port at the end of the day. The total salt mass for each experiment is sum of the mass of salt added to the source $(602 \mathrm{~g})$ and the initial salt amount in the sand column (63 g) due to the fact that the freshwater salt concentration was $0.3 \mathrm{~g} / \mathrm{l}$.

The following observations can be made from Figure 8: a) the total initial mass in both columns was $665 \mathrm{~g}$ with $602 \mathrm{~g}$ residing in the source area; b) the mass of salt recorded within the source in the two experiments was nearly identical at all times; c) the mass distribution within the porous media, after one day, was quite similar for Experiments 1a and $1 \mathrm{~b}$ ( $402 \mathrm{~g}$ and $409 \mathrm{~g}$ ); d) the salt mass accounted by the center of the column in Experiments $1 \mathrm{a}$ and $1 \mathrm{~b}$ after one day (402 $\mathrm{g}$ and $409 \mathrm{~g}$ ) were much less than the total salt mass of the system (665 $\mathrm{g}$ ), and this showed that approximately one third of the salt was moving through other parts of the column and not through the center; e) the salt mass travelling through the center of the column in Experiments $1 \mathrm{a}$ and $1 \mathrm{~b}$ (270 $\mathrm{g}$ and $286 \mathrm{~g}$ ) was much less after five days, compared to what was travelling through the center after one day, and this indicated that the salt was also moving laterally or radially in the porous media which is unlikely to occur if the main transport mechanism was molecular diffusion; f) the total mass recorded in the source and the center of the column in Experiments $1 \mathrm{a}$ and $1 \mathrm{~b}$ after 10 days were $478 \mathrm{~g}$ and $233 \mathrm{~g}$, respectively, which shows a remarkable difference in the salt distribution patterns within the porous media during the two experiments; g) a lot more salt mass (197 g) had sunk to Port 5 in Experiment 1a as compared to Experiment $1 \mathrm{~b}(39 \mathrm{~g})$; h) the salt mass distribution in the two experiments was again very similar after 15 days. These observations leads to three important conclusions: 1) Under unstable conditions with free convection, the rate of transport of salt from the source to the porous media is deterministic or predictable as it was nearly equal in the two experiments at all times, 2) the mass transport through the porous media is stochastic or unpredictable, as the salt may follow very different patterns through the porous media even under two identical scenarios, and 3) the stochastic transport can be attributed to the fact that the main transport mechanism of the salt through porous media, under unstable conditions, is fingering and not molecular diffusion, and because the distribution and size of the fingers that may develop in the porous media, could be quite different even under identical hydrologic conditions. In other words, while one may be able to predict the rate of salt mass that is transported from the source to the porous media, it is not possible to predict how this salt mass will be distributed in the porous media after a given time much like it is not possible to accurately predict the movement of a DNAPL through porous media. In the case of the DNAPL, the stochastic nature of transport is due to the random location and sizes of the macro-pores in the porous media, whereas in the case of unstable salt transport, it is because of the random locations and sizes of the fingers.

\section{Comparison of breakthrough curves for Experiment 2}

The breakthrough curves measured at different ports for Experiments $2 \mathrm{a}, 2 \mathrm{~b}$, and $2 \mathrm{c}$ are shown in Figures 9-11, respectively, and compared for each port in Figures 12-16. These comparisons indicate that:

- The breakthrough curves of Experiments $2 a, 2 b$ and $2 c$ are quite different from each other for Ports 1 through 4; only the breakthrough curves at Port 5 are somewhat similar. This phenomenon is similar to what was observed in the fixed mass experiments in that the breakthrough curves at the lowest port, Port 5, were similar while they were different at the other four ports.

- The breakthrough curves at all ports were not smooth and exhibited that the salt concentration was randomly fluctuating during the first five to ten days at Ports 1 through 4. These fluctuations were not quite as prominent at Port 5 .

- All breakthrough curves became relatively smooth after a period of approximately 12 days. This could be because with time the fingers coalesce and the solution moves down more in the form of a traditional plume [25]. In other words, the plume begins to "stabilize" after a certain time.

- As in Experiment 1, the salinity at the two lower ports (Ports 4 and 5) became higher than the salinity at the upper ports (Ports 1 and 2) after a period of 5 days (Figures 9 and 10), and stayed higher till the end of the experiment. Schincariol et al. [15] also observed that the lower part of the column led higher concentration in their plume experiments.

\section{Conclusions and Discussion}

Two identical fixed mass experiments, with a salt source on top of a column of porous media, were conducted under unstable conditions to simultaneously study, for the first time: a) the salt transport that occurs from a salt source to the porous media, and b) the vertical salt transport within the porous media itself. The rate of mass transport from the source to the porous media was observed by measuring the salt concentration within the source at various times, while the salt transport through the porous media was documented measuring breakthrough curves at five locations. Results, using mass analysis, showed that while the salt transport from the source to the porous media was deterministic in the sense that both experiments produced identical rates of mass transport from the source to the porous media, the salt transport through the porous media was stochastic since the observed breakthrough curves at the five locations were considerably different. The salt transport through the porous media was also observed by measuring breakthrough curves at five locations in three identical continuous injection experiments. The measured breakthrough curves in the continuous injection experiments were also very different supporting the results of the fixed mass experiments that the mass transport through the porous media, under unstable conditions, is stochastic. The implications of these findings are that while one can predict the amount of salt that would enter from a salt source into the underlying porous media with a great deal of certainty under unstable conditions, one cannot predict the rate or pattern of salt transport through the porous media itself. Other key findings were:

a) The differences in the breakthrough curves were highest in the upper regions of the porous media and decreased as the salt traversed downward. This phenomenon can be attributed to the fact that fingers tend to coalesce as they move downwards resulting in the movement of the salt mass not being as random at the bottom as at the top. The coalescing of fingers, under unstable transport conditions, has also been observed by several other researchers including Bachmat et al. [12] who saw finger coalescing in their dye experiments, and Simmons et al. [26] and Kneafsey et al. [21] who observed the coalescence of fingers in their Hele-Shaw cell experiments.

b) The salt was not just moving vertically but also laterally. This 


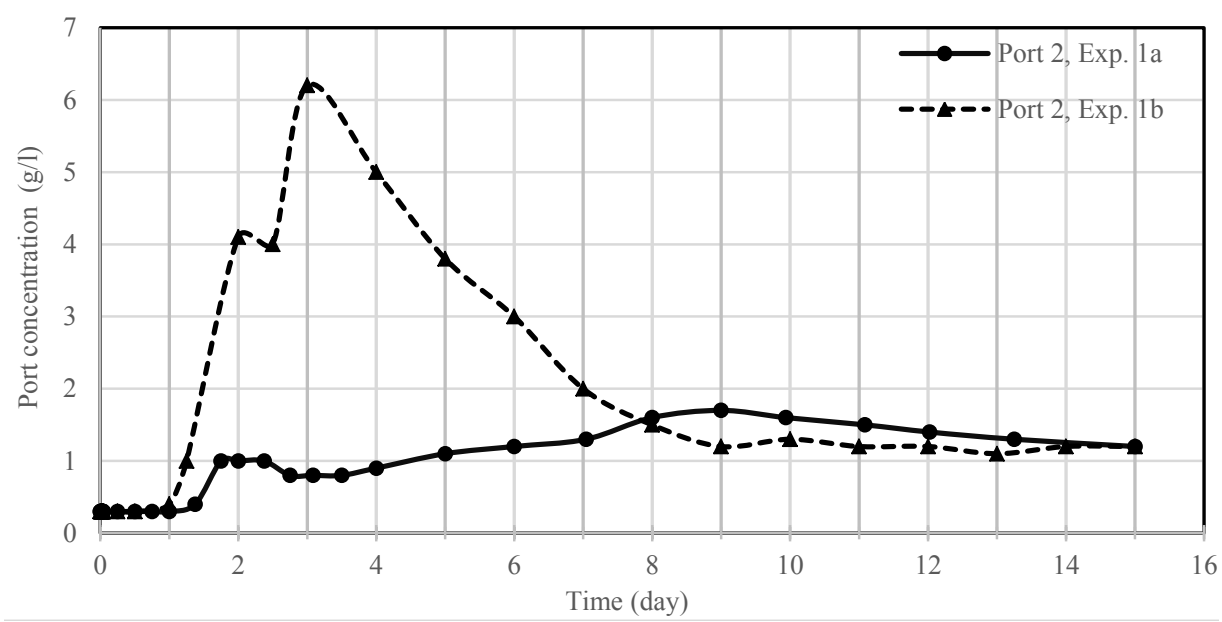

Figure 4: Comparison of breakthrough curves at Port 2 for Experiments 1a, and 1b.

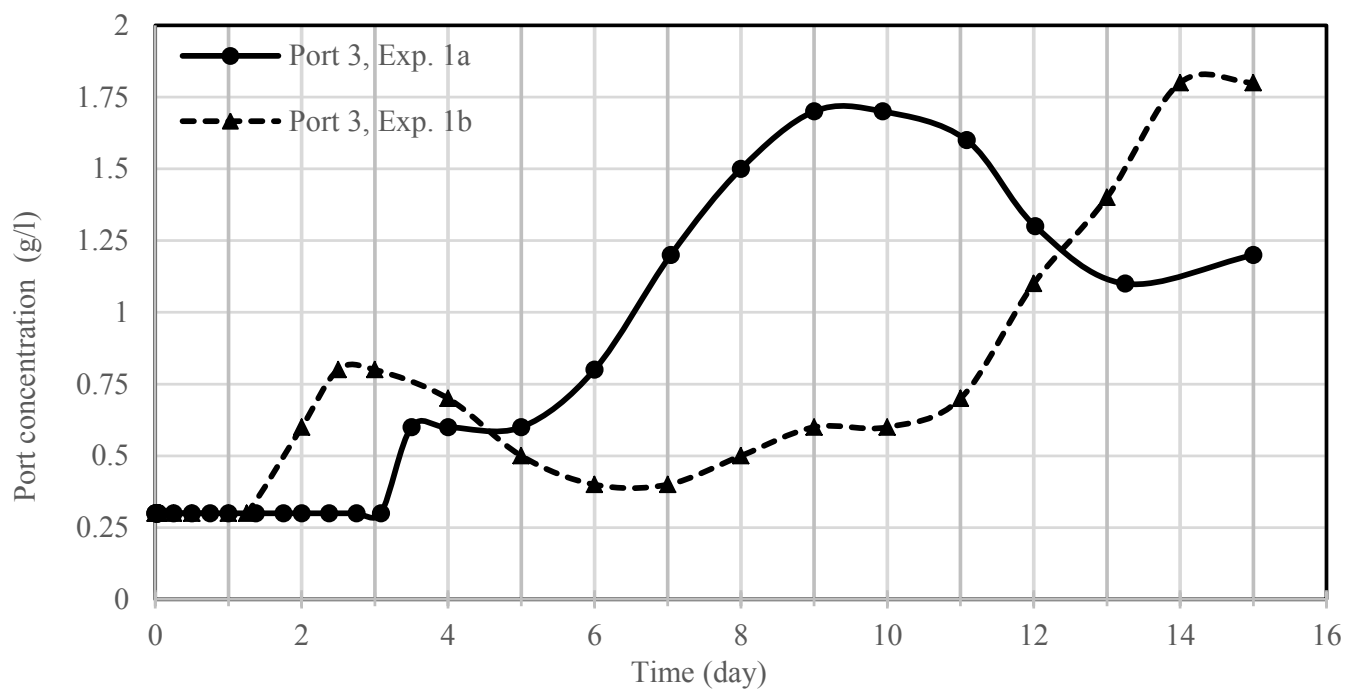

Figure 5: Comparison of breakthrough curves at Port 3 for Experiments 1a, and 1b.

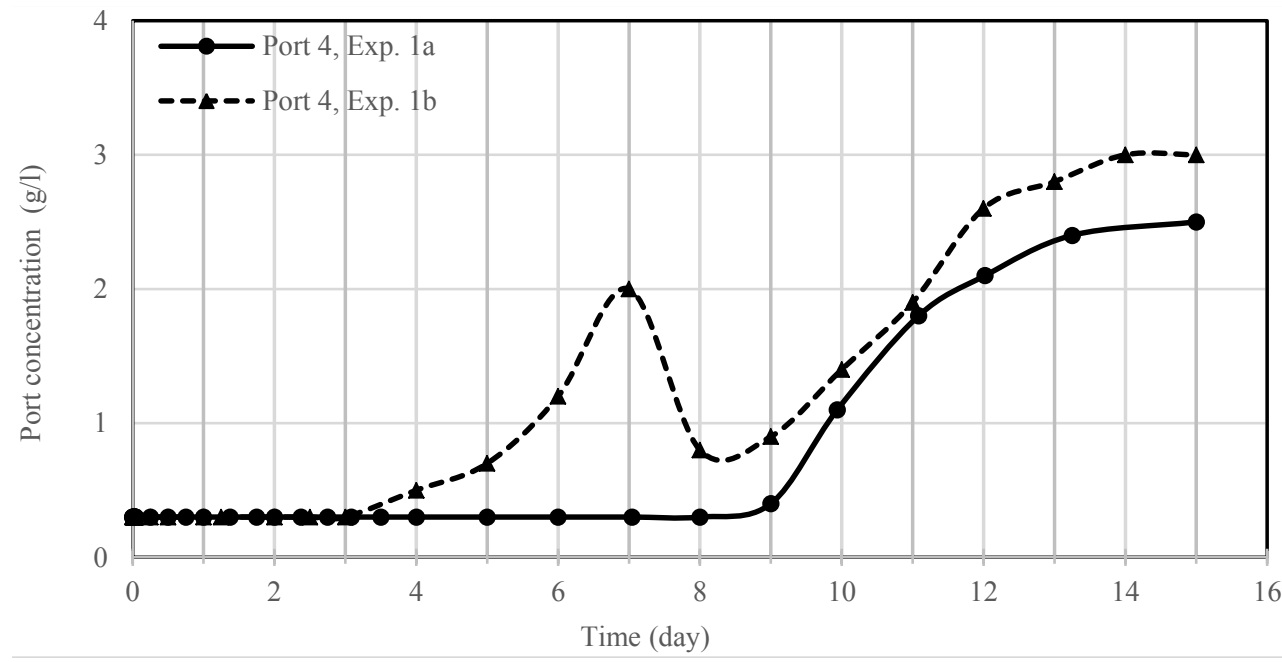

Figure 6: Comparison of breakthrough curves at Port 4 for Experiments 1a, and 1b. 


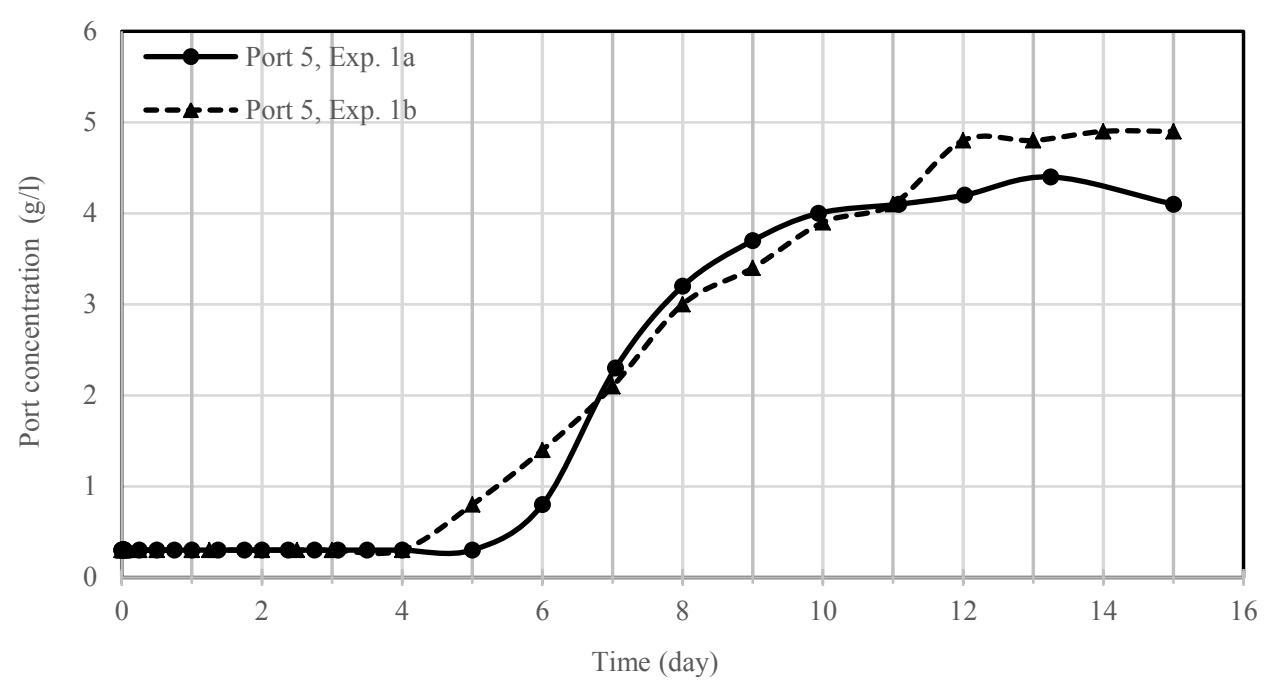

Figure 7: Comparison of breakthrough curves at Port 5 for Experiments 1a, and 1b.

Time (day) 0

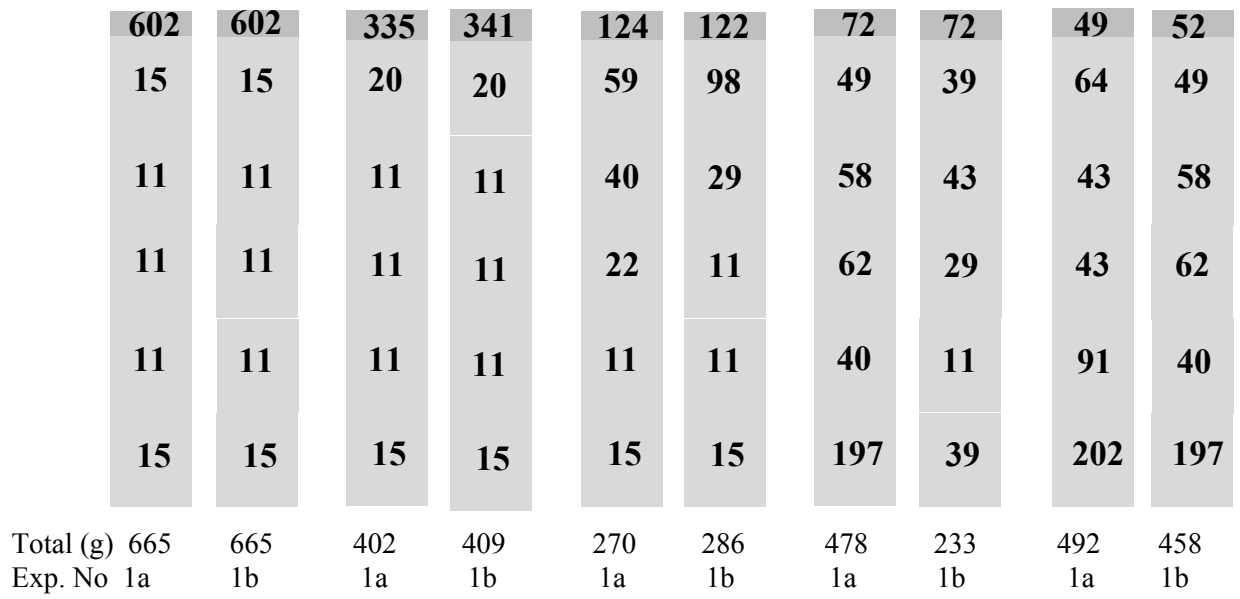

Figure 8: Mass distribution in the middle sand column for Experiment $1 \mathrm{a}$ and $1 \mathrm{~b}$ in different days; the mass in the top cell represents the salt mass within the source area.

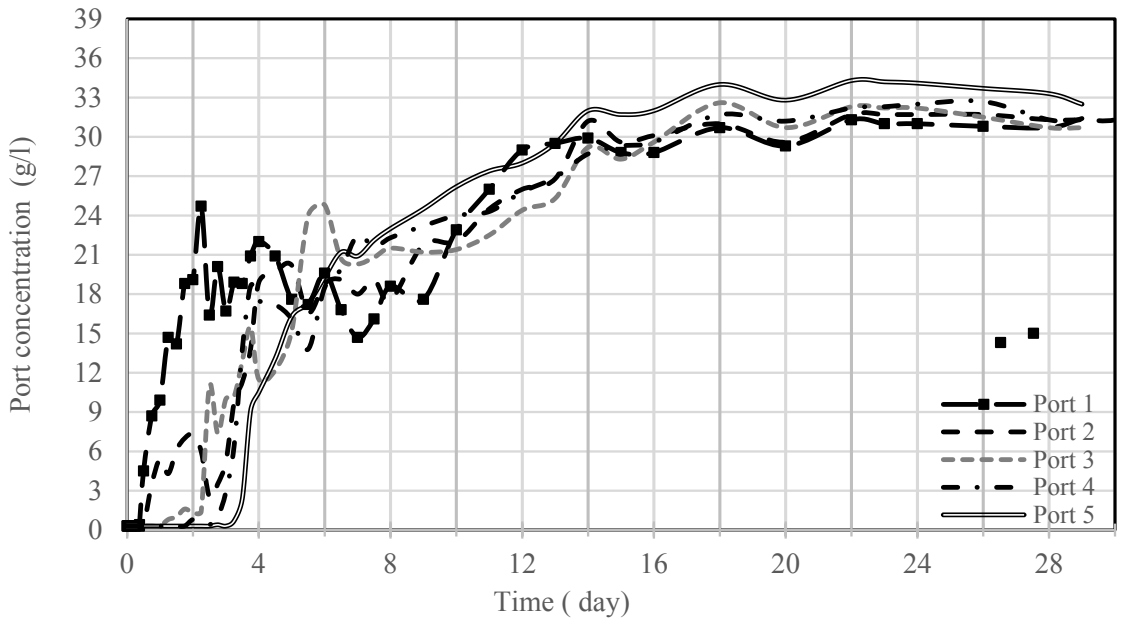

Figure 9: Measured breakthrough curves at five ports for Experiment 2a. 


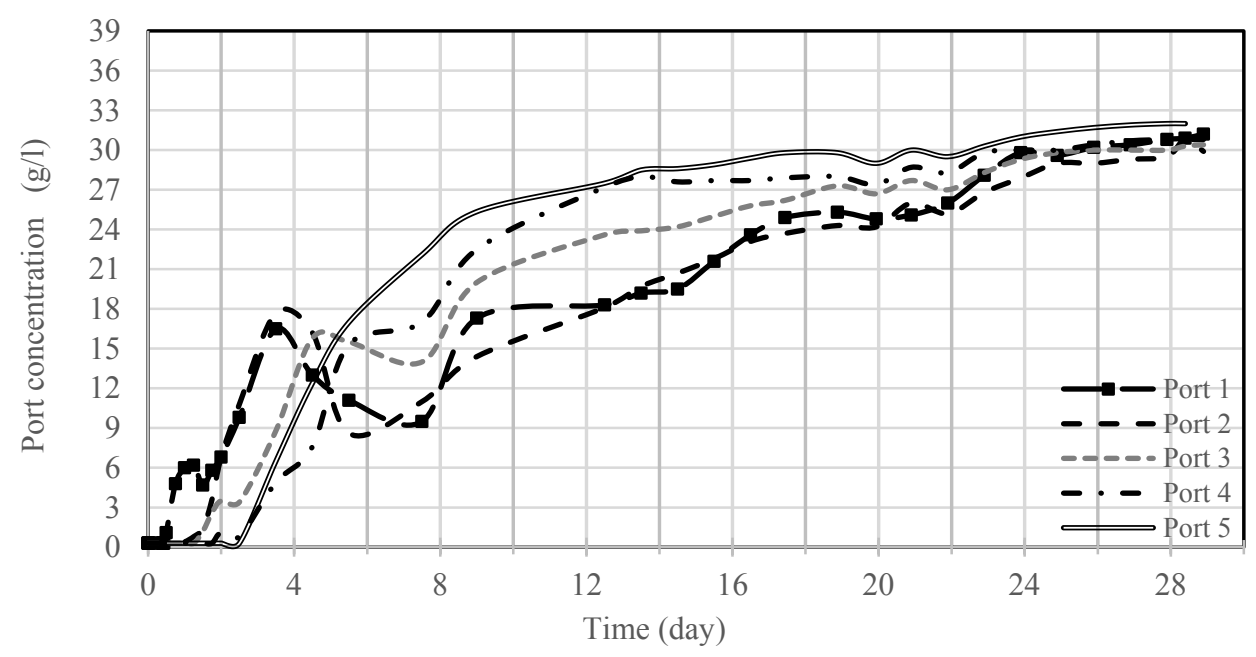

Figure 10: Measured breakthrough curves at five ports for Experiment 2b.

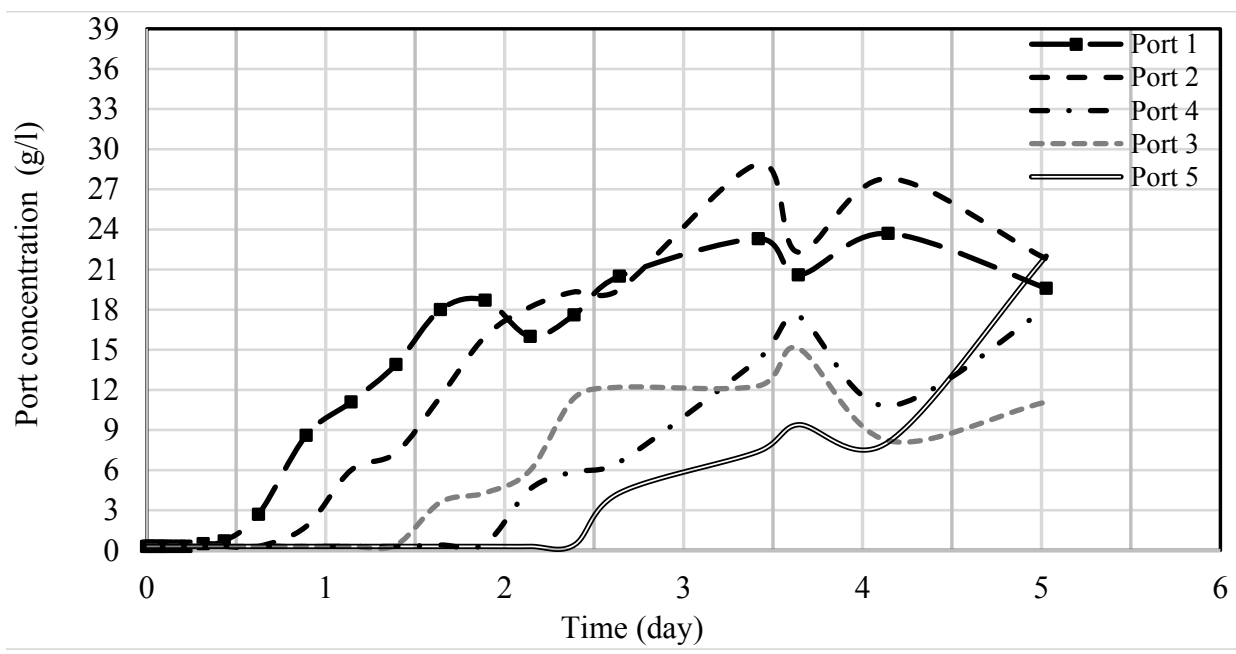

Figure 11: Measured breakthrough curves at five ports for Experiment 2c.

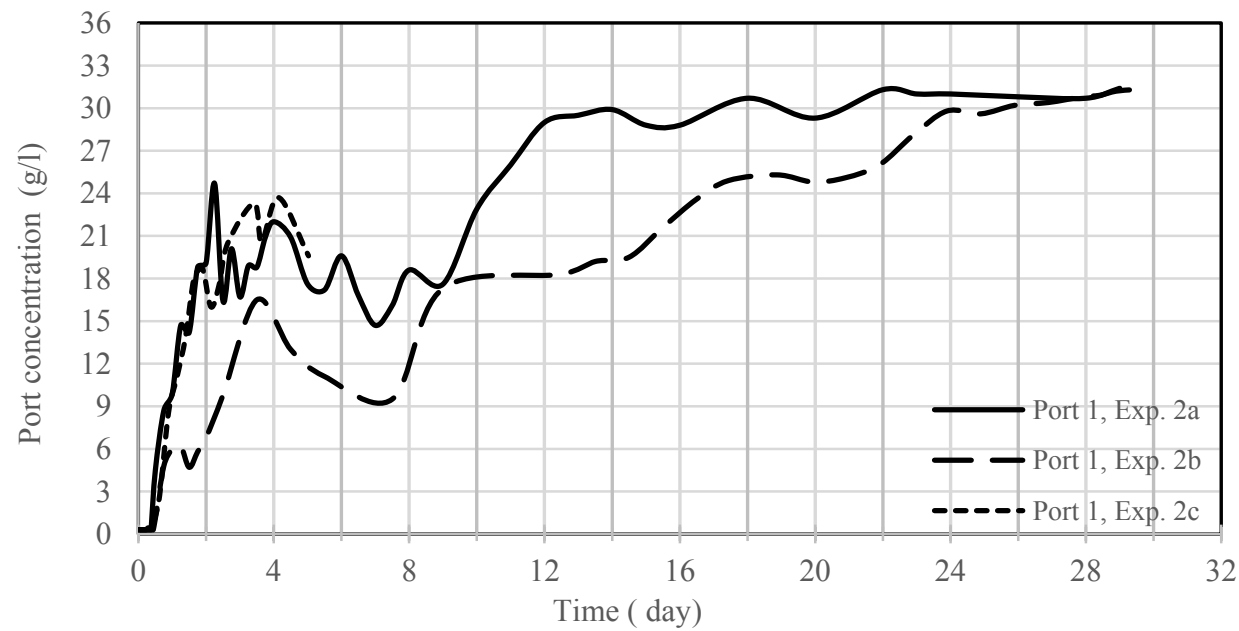

Figure 12: Comparisons of measured breakthrough curves at Port 1 for Experiments 2a, 2b, and 2c. 


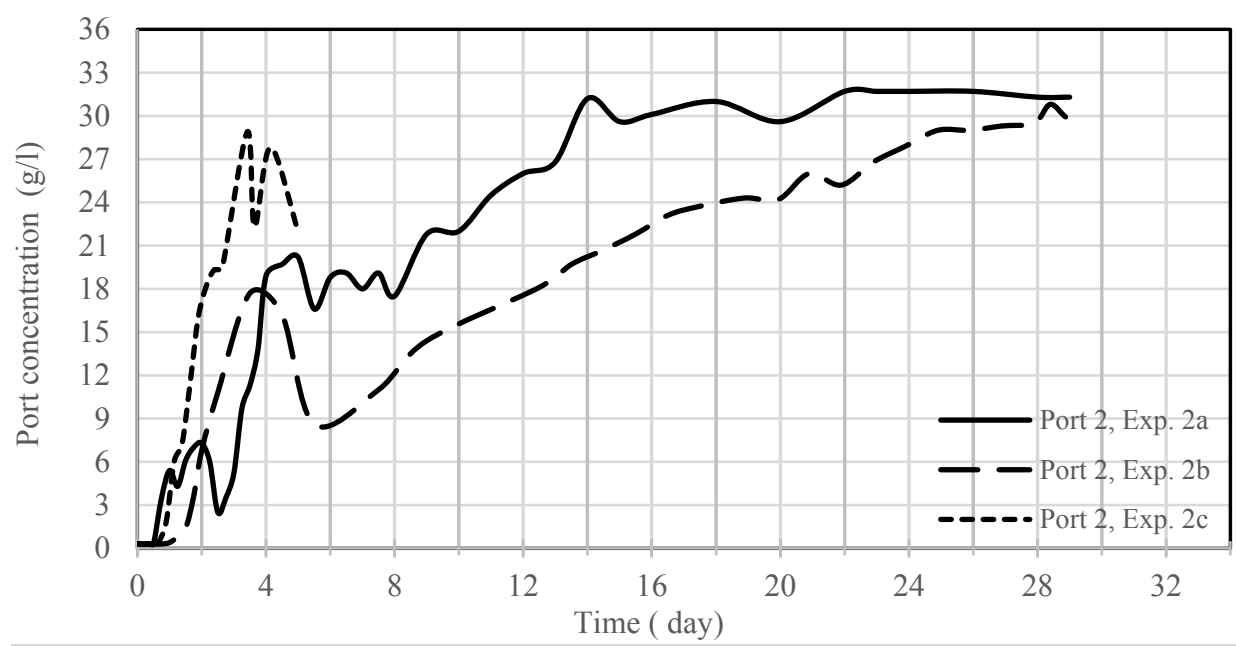

Figure 13: Comparisons of measured breakthrough curves at Port 2 for Experiments 2a, 2b, and 2c.

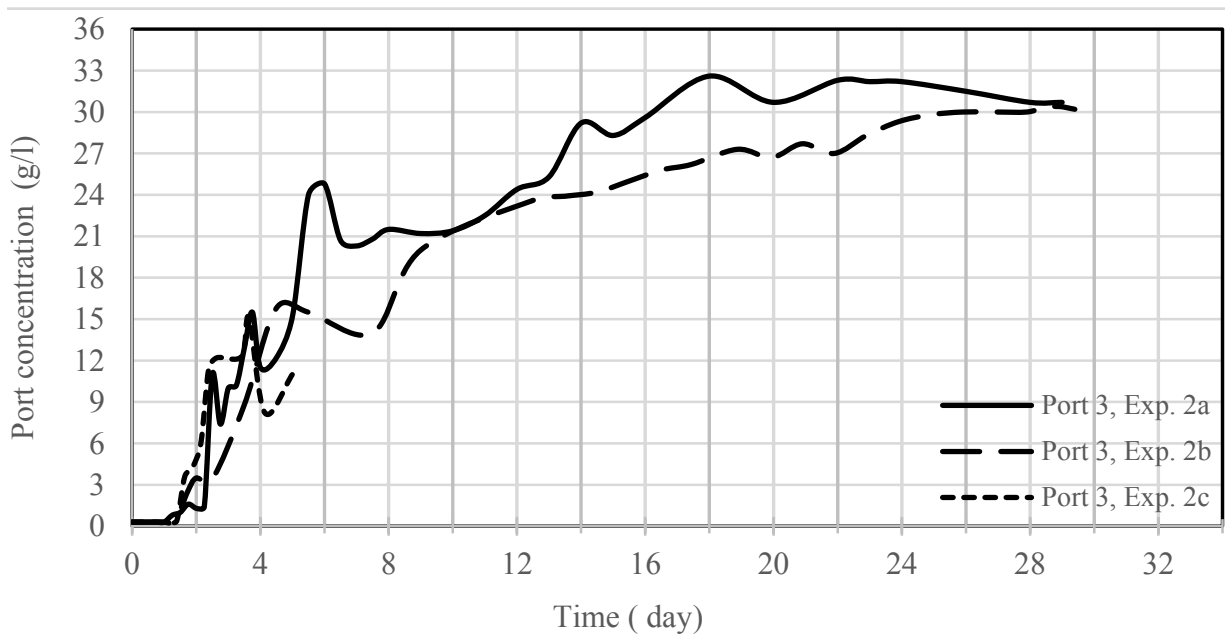

Figure 14: Comparisons of measured breakthrough curves at Port 3 for Experiments 2a, 2b, and 2c.

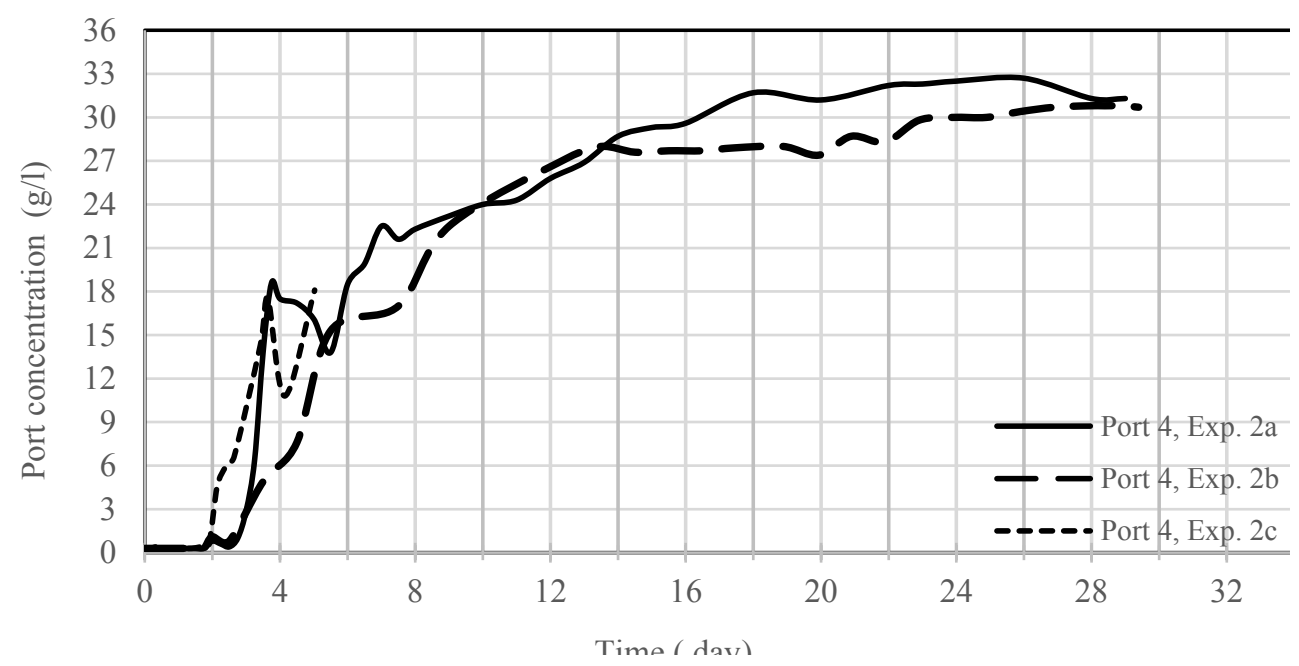

Figure 15: Comparisons of measured breakthrough curves at Port 4 for Experiments 2a, 2b, and 2c. 


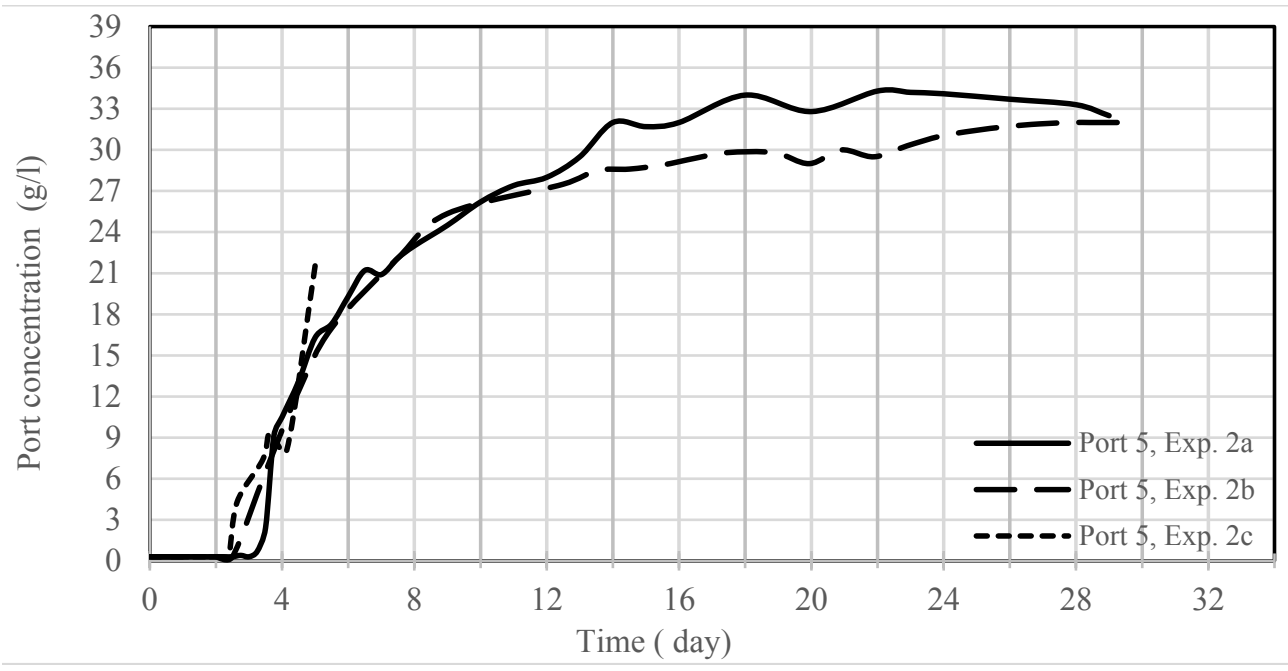

Figure 16: Comparisons of measured breakthrough curves at Port 5 for Experiments 2a, 2b, and 2c.

was evident from mass analyses conducted in the fixed mass experiments which showed that the total mass in the center of the column decreased by more than $100 \mathrm{~g}$. This reduction of mass in the center of the column could only occur because of lateral transport. The lateral transport of the salt can again be attributed to the random nature of finger coalescing that goes on as the salt travels through the porous media.

c) The breakthrough curves in the continuous injection experiments were oscillating in the first five to ten days and smoothened as the experiment continued. The oscillation in the breakthrough curves could also be attributed to the random nature of finger forming and coalescing that occurs as the salt travels through the porous media.

d) The transport of salt through porous media under unstable conditions is somewhat similar to a DNAPL in that the salt takes random pathways in the form of fingers, while the DNAPL takes random pathways due to the presence of macro-pores. The random movement of the salt through the porous media as well as the fact that it sinks to the bottom, similar to a DNAPL, results in an uneven salt concentration within the porous media which cannot be predicted with any certainty.

\section{References}

1. Kimmel GE, Braids OC (1980) Leachate plumes in ground water from babylon and islip landfills, long island, new york. Geological Survey (US), Suffolk County (NY), Department of Environmental Control Washington: US Govt Print Off.

2. Kooper WF (1983) Density flow in the water supply package below the dump site in Noordwijk. [S.I.]: National Institute for Drinking Water.

3. Hubao Z, Scwartz FW (1995) Multispecies contaminant plumes in variable density flow systems. Water Resour Res 31: 837-847.

4. Simmons CT, Narayan KA (1997) Mixed convection processes below a saline disposal basin. J Hydrol 194: 263-285.

5. Kooi HJ, Leijnse GA (2000) Modes of seawater intrusion during transgressions. Water Resour Res 36: 3581-3589.

6. Anthony SJ, Turner JV (2001) Density-dependent surface water-groundwater interaction and nutrient discharge in the swan-canning estuary. Hydrol Process 15: $2595-2616$

7. Katsuyuki F, Iba T, Fujihara Y, Watanabe T (2009) Modeling interaction of fluid and salt in an aquifer/lagoon system. Ground Water 47: 35-48.
8. Viezzoli A, Tosi L, Teatini P, Silvestri S (2010) Surface water-groundwater exchange in transitional coastal environments by airborne electromagnetics: The venice lagoon example. Geophys Res Lett p: 37.

9. Casper K, Sonnenborg TO, Auken E, Jorgensen F (2011) Salinity distribution in heterogeneous coastal aquifers mapped by airborne electromagnetics. Vadose Zone J 10: 125-135.

10. Pandit A, Ali N, and Heck $H$ (2011) Spatial calibration of vertical hydraulic conductivity below an estuary. J Hydrol Eng 16: 763-771.

11. Pandit A, Ali N, Heck $H$, and Mamoua K (2016) Estimation of submarine groundwater discharge into the Indian River lagoon. Austin J Irrigation 2: 1-8.

12. Bachmat $Y$, Elrick DE (1970) Hydrodynamic instability of miscible fluids in a vertical porous column. Water Resour Res 6: 156-171.

13. Gebhart B (1988) Transient response and disturbance growth in vertical buoyancy-driven flows. J Heat Transfer 110: 1166-1174.

14. Wooding RA (1959) The stability of a viscous liquid in a vertical tube containing porous material. Proceedings of the Royal Society. A, Mathematical, Physical, and Engineering Sciences 252: 120-134.

15. Schincariol RA, Schwartz FW (1990) An experimental investigation of variable density flow and mixing in homogeneous and heterogeneous media. Water Resour Res 26: 2317- 2329.

16. Webster IT, Norquay SJ, Ross FC, Wooding RA (1996) Solute exchange by convection within estuarine sediments. Estuar Coast Shelf Sci 42: 171-83.

17. Simmons CT, Pierini ML, Hutson JL (2002) Laboratory investigation of variabledensity flow and solute transport in unsaturated-saturated porous media. Transport in Porous Media 47: 215-244.

18. Wood M, Simmons CT, Hutson JL (2004) A breakthrough curve analysis of unstable density-driven flow and transport in homogeneous porous media. Water Resour Res 40: W035051-9.

19. Post VEA, Simmons CT (2010) Free convective controls on sequestration of salts into low-permeability strata: Insights from sand tank laboratory experiments and numerical modeling. Hydrogeol J 18: 39-54.

20. Klaus J, Oswald S, Held R, Kinzelbach W (2006) Numerical simulation of threedimensional saltwater-freshwater fingering instabilities observed in a porous medium. Adv Water Resour 29: 1690-1704.

21. Kneafsey TJ, Pruess K (2010) Laboratory flow experiments for visualizing carbon dioxide-induced, density-driven brine convection. Transport in Porous Media 82: 123-139.

22. Goswami RR, Clement TP, Hayworth JH (2012) Comparison of numerical techniques used for simulating variable-density flow and transport experiments. J Hydrol Eng 17: 272-282. 
Citation: Mamoua K, Pandit A, Heck H (2017) Stochastic Nature of Salt Mass Transport in Porous Media Under Unstable Conditions. Hydrol Current Res 8: 278. doi: 10.4172/2157-7587.1000278

23. Kamal M, Pandit A, Howell H (2016) Physical and Numerical Modeling of Unstable Flow Due to Heavier Saltwater Overlying Freshwater. EWRI Congress West Palm Beach Florida.

24. Mulqueen J, Kirkham D (1972) Leaching of a surface layer of sodium chloride into tile drains in a sand-tank model. Soil Sci Soc Am 36: 3-9.
25. Simmons CT, Fenstemaker TR, Sharp JM (2001) Variable-density groundwater flow and solute transport in heterogeneous porous media: Approaches, resolutions and future challenges. J Contaminant Hydrol 52: 245-275.

26. Simmons CT, Narayan KA, Wooding RA (1999) On a test case for densitydependent groundwater flow and solute transport models: The Salt Lake problem. Water Resour Res 35: 3607-3620. 